Research article

\title{
Sampling effects on the identification of roadkill hotspots: Implications for survey design
}

\author{
Sara M. Santos ${ }^{\mathrm{a}, ~ *}$, J.Tiago Marques ${ }^{\mathrm{a}, \mathrm{b}}$, André Lourenço ${ }^{\mathrm{c}}$, Denis Medinas ${ }^{\mathrm{a}}$, \\ A.Márcia Barbosa ${ }^{\mathrm{d}}$, Pedro Beja ${ }^{\mathrm{e}}$, António Mira ${ }^{\mathrm{a}}$ \\ ${ }^{a}$ Conservation Biology Lab (UBC), Research Center in Biodiversity and Genetic Resources (CIBIO-UE), Pole of Évora, Research Group in Applied Ecology, \\ University of Évora, Department of Biology, Mitra, 7002-554 Évora, Portugal \\ ${ }^{\mathrm{b}}$ Centre for Environmental Biology (CBA), Faculty of Sciences, University of Lisbon, Campo Grande, 1749-016 Lisboa, Portugal \\ ${ }^{\mathrm{c}}$ Research Center in Biodiversity and Genetic Resources (CIBIO), University of Porto, Campus Agrário de Vairão, 4485-661 Vairão, Portugal \\ ${ }^{\mathrm{d}}$ Research Center in Biodiversity and Genetic Resources (CIBIO-UE), Pole of Évora, Research Group in Climate Change and Biodiversity, University of Évora, \\ 7004-890 Évora, Portugal \\ e EDP Biodiversity Chair, CIBIO - Research Center in Biodiversity and Genetic Resources, University of Porto, Campus Agrário de Vairão, Rua Padre Armando \\ Quintas, 4485-661 Vairão, Portugal
}

\section{A R T I C L E I N F O}

\section{Article history:}

Received 26 June 2014

Received in revised form

6 July 2015

Accepted 16 July 2015

Available online $\mathrm{xxx}$

\section{Keywords:}

Monitoring

Sampling design

Spatial accuracy

Wildlife road mortality

\begin{abstract}
A B S T R A C T
Although locating wildlife roadkill hotspots is essential to mitigate road impacts, the influence of study design on hotspot identification remains uncertain. We evaluated how sampling frequency affects the accuracy of hotspot identification, using a dataset of vertebrate roadkills $(n=4427)$ recorded over a year of daily surveys along $37 \mathrm{~km}$ of roads. "True" hotspots were identified using this baseline dataset, as the 500 -m segments where the number of road-killed vertebrates exceeded the upper 95\% confidence limit of the mean, assuming a Poisson distribution of road-kills per segment. "Estimated" hotspots were identified likewise, using datasets representing progressively lower sampling frequencies, which were produced by extracting data from the baseline dataset at appropriate time intervals (1-30 days). Overall, $24.3 \%$ of segments were "true" hotspots, concentrating $40.4 \%$ of roadkills. For different groups, "true" hotspots accounted from $6.8 \%$ (bats) to $29.7 \%$ (small birds) of road segments, concentrating from $<40 \%$ (frogs and toads, snakes) to >60\% (lizards, lagomorphs, carnivores) of roadkills. Spatial congruence between "true" and "estimated" hotspots declined rapidly with increasing time interval between surveys, due primarily to increasing false negatives (i.e., missing "true" hotspots). There were also false positives (i.e., wrong "estimated" hotspots), particularly at low sampling frequencies. Spatial accuracy decay with increasing time interval between surveys was higher for smaller-bodied (amphibians, reptiles, small birds, small mammals) than for larger-bodied species (birds of prey, hedgehogs, lagomorphs, carnivores). Results suggest that widely used surveys at weekly or longer intervals may produce poor estimates of roadkill hotspots, particularly for small-bodied species. Surveying daily or at two-day intervals may be required to achieve high accuracy in hotspot identification for multiple species.
\end{abstract}

(c) 2015 Elsevier Ltd. All rights reserved.

\section{Introduction}

Roads are often a source of considerable wildlife mortality,

\footnotetext{
* Corresponding author. Unit of Conservation Biology (UBC), Research Center in Biodiversity and Genetic Resources (CIBIO/UE), University of Évora, Department of Biology, Mitra, 7002-554 Évora, Portugal.

E-mail addresses: saramlsantos@yahoo.com (S.M. Santos), jtiagomarques@ gmail.com (J.Tiago Marques), andrelourenc0300@gmail.com (A. Lourenço), denimedinas@gmail.com (D. Medinas), barbosa@uevora.pt (A.Márcia Barbosa), pbeja@cibio.up.pt (P. Beja), amira@uevora.pt (A. Mira).
}

which may have significant impacts on animal populations (Coffin, 2007; Forman et al., 2003; Trombulak and Frissell, 2000). To reduce roadkill rates, many projects involve the implementation of specific mitigation measures, including the construction of wildlife crossings (e.g. over or underpasses), the use of fences to keep wildlife away from roads or to guide them to safe crossing points, and the installation of animal crossing signs (Clevenger et al., 2003; Glista et al., 2009; Mata et al., 2008). Since mitigation structures are expensive (Glista et al., 2009; Huijser et al., 2009; Iuell et al., 2003), they must be placed where they are most effective. Therefore, accurately locating roadkill hotspots, i.e. segments of roads with 